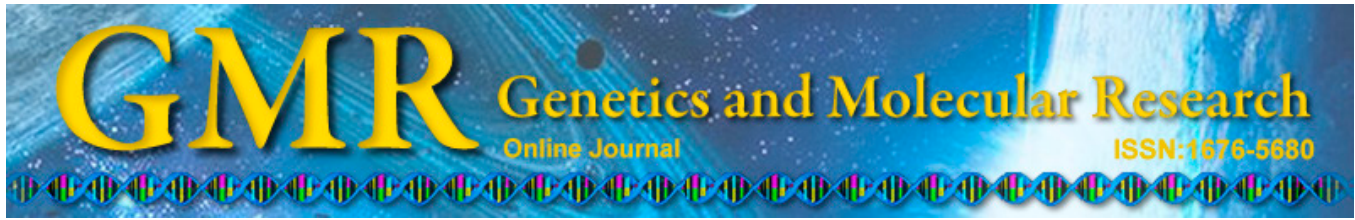

\title{
Selection and molecular identification of fungal isolates that produce xylanolytic enzymes
}

\author{
M. Alvarez-Navarrete ${ }^{1}$, G.E. Reyna López ${ }^{2}$, A. Flores-García ${ }^{1}$, \\ R. López Gómez ${ }^{1}$ and M.M. Martínez-Pacheco ${ }^{1}$ \\ ${ }^{1}$ Instituto de Investigaciones Químico-Biológicas, \\ Universidad Michoacana de San Nicolás de Hidalgo, Morelia, \\ Michoacán, México \\ ${ }^{2}$ División de Ciencias Naturales y Exactas, Universidad de Guanajuato, \\ Guanajuato, México
}

Corresponding author: M.M. Martínez-Pacheco

E-mail: mpacheco@umich.mx

Genet. Mol. Res. 14 (3): 8100-8116 (2015)

Received December 1, 2014

Accepted February 20, 2015

Published July 17, 2015

DOI http://dx.doi.org/10.4238/2015.July.17.19

\begin{abstract}
Xylan is a heteropolysaccharide and its complete hydrolysis involves a complex set of xylanolytic enzymes. Fungal xylanases have been widely used in the holocellulose industry to obtain by-products or for its elimination. The aim of this study was to select and identify filamentous fungi from different ecosystems that produce extracellular xylanases showing biotechnological potential. One hundred three fungal isolates were obtained from orchard, horticultural, and forest ecosystems. The ability of fungi to degrade xylan was measured by quantifying their xylanolytic indices after growth on solid culture media and their extracellular xylanolytic and cellulolytic activities after submerged fermentation. All fungal isolates grew on solid medium supplemented with xylan as the sole carbon source, but only $44 \%$ of isolates showed xylanolytic indices greater than 1.0. In submerged fermentation, $39 \%$ of the fungi tested showed no cellulolytic activity.
\end{abstract}


Filamentous fungi were chosen from correspondence analysis and were identified by molecular tools using internal transcribed spacers. One of the 9 isolates selected belonged to the Phoma genus and the remaining were from the Fusarium genus. Fusarium solani (isolate 59) showed the highest xylanolytic index $(0.964 \pm 0.042)$, rapid growth on solid medium $(1.233 \pm 0.050 \mathrm{~cm} /$ day), significant xylanolytic activity $(3.823$ $\pm 0.210 \mathrm{U} / \mathrm{mg}$ ), and a total deficiency of cellulolytic activity compared to other fungal isolates. In the zymogram, a clear zone was observed, indicating that $F$. solani possesses at least 1 xylanase. Fusarium solani was selected for its ability to produce extracellular xylanases with biotechnological potential.

Key words: Cellulase; Fungal identification; Fungal isolate; Xylanase; Submerged fermentation; Xylanolytic index

\section{INTRODUCTION}

Microbial xylanases form an enzyme complex that catalyzes xylan hydrolysis to xylan oligomers, xylobiose, and xylose. Filamentous fungi are particularly interesting because they secrete significantly higher levels of these enzymes into the medium than yeasts and bacteria. It is generally known that the key enzyme in the xylanolytic system is endo-1,4- $\beta$ xylanase (1,4-D-xylan xylohydrolase; EC 3.2.1.8), which cleaves internal glycosidic bonds from 1,4- $\beta$-D-xylan chains. Xylanases have been widely used to treat lignocellulosic materials from agricultural, agroindustrial, and municipal residues (Khandeparker and Numan, 2008). Locally, the commercial imbalance between export and import of enzymes provides an area of biotechnological opportunity (SIAVI, 2013), where it is possible to compete with an optimal process to produce xylanases based in the fermentation of agroindustrial wastes with native microorganisms. Commercial xylanase preparations are not equally effective for the hydrolysis of lignocellulosic material that has been industrially processed. Thus, there is significant industrial competition for technological developments pertaining to xylanases so as to ensure comprehensive utilization of lignocellulosic biomass and to obtain products of commercial interest (Dhiman et al., 2008). The competition also increases because the complexity and variability of cell wall polysaccharides are now very well understood.

The cost of enzymes in industry is very high. They represent a significant percentage of the total cost of lignocellulosic materials in hydrolysis processes. Therefore, studies have focused on reducing the cost of enzyme production (Klein-Marcuschamer et al., 2012). Approaches for achieving this goal are numerous, but the exploration of organisms with new enzymes combined with factors related with production, such as selection of suitable substrates, modification of culture conditions, recycling enzymes, and process redesign, is limited.

Several studies have been conducted to search for filamentous fungi from different ecosystems that produce efficient xylanolytic complexes. This has been done for fungi associated with plants (pathogenic and nonpathogenic), waste-degrading fungi with xylanase extracts that lack any protease activity, soil fungi, and marine fungi (obligate and facultative, able to produce cellulase-free thermostable xylanase, and active at alkaline $\mathrm{pH}$ ) (Raghukumar et al., 2004; Chipeta et al., 2005; King et al., 2011). 
Current studies are being conducted to identify efficient xylanolytic enzymes for use in industrial applications. Only a small percentage of fungal species has been studied for their biological diversity, and an even smaller percentage has been investigated in relation to xylanase production.

Given the abundance of fungal diversity, it is possible to isolate and culture a large number of species that have not been thoroughly studied. Reliable taxonomy is crucial for biodiversity assessment and habitat categorization based on species type. The criteria used to delimit and identify species of plant pathogenic fungi have changed dramatically with the development of modern molecular tools. Currently, multigene sequencing and phylogenetic analysis have become routine procedures for identifying new fungal species, particularly those that lack distinctive morphological characters (Cai et al., 2011). Molecular identification based on fungal DNA sequences has become an essential component of fungal ecology research over the last 15-20 years and has provided new insights into the diversity and ecology of many different fungal groups. The aim of this study was to select and identify filamentous fungi from several ecosystems capable of producing extracellular xylanases with biotechnological potential.

\section{MATERIAL AND METHODS}

\section{Collection of fungal isolates}

One hundred three fungal isolates were obtained from soil samples and plant debris from orchard (16\%), horticultural (76\%), and forest ecosystems ( $8 \%$ ). The orchard ecosystems included avocado, lemon, and macadamia, located at $19^{\circ} 25^{\prime} 00^{\prime \prime} \mathrm{N}, 102^{\circ} 04^{\prime} 00^{\prime \prime} \mathrm{W}$. The horticultural ecosystems included beans, corn, garlic, sorghum, and wheat fields from several regions located at $22^{\circ} 35^{\prime} 00^{\prime \prime} \mathrm{N}, 102^{\circ} 15^{\prime} 00^{\prime \prime} \mathrm{W}$. The forest ecosystems were located at $20^{\circ} 18^{\prime} 0^{\prime \prime} \mathrm{N}$, $101^{\circ} 10^{\prime} 59^{\prime \prime} \mathrm{W}$. Fungi were categorized using a progressive numeric key (1-103). Thirty-seven fungal isolates were previously characterized using classic taxonomical tools.

\section{Fungal culture}

Maintenance of fungal monosporic isolates and non-sporulating fungi (Mycelia sterilia) was conducted using spores or segments of young colonies on potato dextrose agar medium. The basal medium (BM) contained the following per liter: $5 \mathrm{~g} \mathrm{C}_{4} \mathrm{H}_{12} \mathrm{~N}_{2} \mathrm{O}_{6}$ (ammonium tartrate), $1 \mathrm{~g} \mathrm{KH}_{2} \mathrm{PO}_{4}, 0.5 \mathrm{~g} \mathrm{MgSO}_{4} \cdot 7 \mathrm{H}_{2} \mathrm{O}, 0.1 \mathrm{~g}$ yeast extract, $0.001 \mathrm{~g} \mathrm{CaCl}_{2} \cdot 2 \mathrm{H}_{2} \mathrm{O}$, and $16 \mathrm{~g}$ agar. Two carbon sources were used, $4 \mathrm{~g} / \mathrm{L}$ dextrose for fungal propagation and $40 \mathrm{~g} / \mathrm{L}$ xylan (Sigma, St. Louis, MO, USA) for xylanolytic index determination. Samples were incubated in the dark at room temperature until use.

\section{Determination of xylanolytic index (XI)}

The BM supplemented with birch wood xylan was inoculated with 3 propagules $(5 \times 5$ $\mathrm{mm}$ ) equidistantly from each other, from BM plates with dextrose previously cultured with the fungus. Petri plates were incubated in the dark at room temperature until the fungal colony diameter was $2 \mathrm{~cm}$. Colonies were then stained with $0.125 \% \mathrm{I}_{2}(\mathrm{w} / \mathrm{v})$ and $0.25 \% \mathrm{KI}(\mathrm{w} / \mathrm{v})$ iodine solution in aqueous solution for $5 \mathrm{~min}$ with gentle agitation. Iodine solution was removed by washing the plate surface twice with triple-distilled water. The complete hydrolysis of xylan 
around the colonies appeared as an opaque yellow area against a blue/reddish or purple color for degraded xylan (Pointing, 1999). The xylan degradation diameter divided by colony diameter was represented as XI. The XI of fungal isolates was determined after measuring colony growth diameter and xylan degradation diameter using the ImageJ software from the NIH. The mean XI value was calculated from 6 replicates.

\section{Xylanase production by fermentation in submerged culture}

Xylanase production was carried out in submerged fermentation. The medium compo-

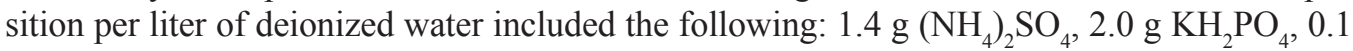
g urea, $0.3 \mathrm{~g} \mathrm{MgSO}_{4} \cdot 7 \mathrm{H}_{2} \mathrm{O}, 0.3 \mathrm{~g} \mathrm{CaCl}_{2}, 5.0 \mathrm{mg} \mathrm{FeSO} \cdot 7 \mathrm{H}_{2} \mathrm{O}, 1.56 \mathrm{mg} \mathrm{MnSO}_{4} \cdot \mathrm{H}_{2} \mathrm{O}, 2.0 \mathrm{mg}$ $\mathrm{CoCl}_{2}, 1.4 \mathrm{mg} \mathrm{ZnSO} \cdot 7 \mathrm{H}_{2} \mathrm{O}, 10 \mathrm{~g}$ beech wood xylan (Sigma), $3 \mathrm{~g}$ dextrose, and $100 \mu \mathrm{L}$ vitamin solution (MEM Vitamins Solution 1000X, Sigma Cell Culture). The culture medium was sterilized by autoclaving at $121^{\circ} \mathrm{C}$ for $15 \mathrm{~min}$. The final $\mathrm{pH}$ of the medium was 5.5. Inoculation was carried out using 4 propagules of $5 \times 5 \mathrm{~mm}$ for each fungal isolate previously grown in BM. Liquid culture media were incubated at room temperature with agitation at $150 \mathrm{rpm}$. Fermentation was performed in triplicate. After 48-h fermentation, the supernatant was separated from the mycelium by filtration using filter paper and was centrifuged at $2814 \mathrm{~g}$ for $3 \mathrm{~min}$. The supernatant was used to quantify xylanolytic and cellulolytic activities and extracellular protein.

\section{Enzymatic assays}

Endo- $\beta$-1,4-xylanase activity was measured following a modified method described by Bailey et al. (1992). The reaction mixture containing $0.6 \mathrm{~mL} 1 \%(\mathrm{w} / \mathrm{v})$ birch wood xylan in $0.05 \mathrm{M}$ sodium citrate buffer, $\mathrm{pH} 5.0$, and $0.6 \mathrm{~mL}$ enzyme properly diluted $(3-50 \mu \mathrm{g} / \mathrm{mL}$ protein) was incubated at $50^{\circ} \mathrm{C}$ for $30 \mathrm{~min}$. The reaction was stopped by boiling the samples in a water bath for $5 \mathrm{~min}$. Next, the samples were centrifuged at $2814 \mathrm{~g}$ rpm for $3 \mathrm{~min}$.

Endo- $\beta$-1,4-glucanase activity was measured following a modified method of Ghose (1987). Aliquots of $0.5 \mathrm{~mL}$ enzyme diluted (3-50 $\mu \mathrm{g} / \mathrm{mL}$ protein) were added to $0.5 \mathrm{~mL} 1 \%$ $(\mathrm{w} / \mathrm{v})$ carboxymethylcellulose $(\mathrm{CMC})$ prepared in $0.05 \mathrm{M}$ sodium citrate buffer, $\mathrm{pH} 5.0$, mixed thoroughly, and incubated at $50^{\circ} \mathrm{C}$ for $30 \mathrm{~min}$.

One unit $(\mathrm{U})$ of endo- $\beta-1,4$-xylanase and endo- $\beta$-1,4-glucanase activity was defined as the amount of enzyme releasing $1 \mu \mathrm{mol}$ reducing sugars per minute when xylose or glucose, respectively, was used as a standard.

\section{Quantification of reducing sugars}

An aliquot of $1 \mathrm{~mL}$ enzymatic reaction mixture was used to quantify the reducing sugars using 3,5-dinitrosalicylic acid reagent. The samples were incubated in a boiling water bath for $15 \mathrm{~min}$. The reducing sugars released were quantified at $540 \mathrm{~nm}$ in a UV-visible spectrophotometer (Cary 50 Bio, Varian, Palo Alto, CA, USA).

\section{Protein quantification}

The extracellular protein from fermentation supernatants was quantified using the 
Lowry method (Lowry et al., 1951). Bovine serum albumin was used as a standard. Each assay was performed in duplicate.

\section{Molecular identification of fungal species}

\section{Genomic DNA extraction}

Genomic DNA extraction was carried out using the modified method of Lin et al. (2001). Fungal isolates were cultured and grown on a cellophane membrane placed on potato dextrose agar medium surface at $25^{\circ} \mathrm{C}$ for 15 days. The mycelium was separated from the cellophane membrane and ground with liquid nitrogen to a fine powder. A sample of $150 \mathrm{mg}$ powdered mycelium was placed in an Eppendorf tube and was mixed thoroughly with $600 \mu \mathrm{L}$ DNA extraction buffer, which contained $100 \mathrm{mM}$ Tris-HCl, $\mathrm{pH}$ 8.0, $50 \mathrm{mM}$ EDTA, $\mathrm{pH}$ 8.0, $500 \mathrm{mM} \mathrm{NaCl}, 2 \% \mathrm{SDS}(\mathrm{w} / \mathrm{v}), 2 \% \beta$-mercaptoethanol $(\mathrm{v} / \mathrm{v})$, and $1 \%$ polyvinylpyrrolindone $(\mathrm{w} / \mathrm{v})$. The samples were incubated at $65^{\circ} \mathrm{C}$ for $15 \mathrm{~min}$. Next, they were centrifuged at 13400 $g$ for $10 \mathrm{~min}$. The supernatant was transferred to a fresh tube and $5 \mu \mathrm{L}$ RNAaseA (Sigma) was added to the mixture. The reaction mixture was incubated at $37^{\circ} \mathrm{C}$ for $10 \mathrm{~min}$. After incubation, an equal volume of phenol:chloroform:isoamyl alcohol (50:49:1) mixture was added and mixed thoroughly. The samples were centrifuged at $13400 \mathrm{~g}$ for $3 \mathrm{~min}$. The supernatant was transferred to a fresh tube and an equal volume of cold isopropanol was added to precipitate the DNA. The samples were incubated at $-80^{\circ} \mathrm{C}$ for $1 \mathrm{~h}$. Samples were centrifuged at $13400 \mathrm{~g}$ for 10 min and the supernatant was discarded. The DNA pellet was washed with $70 \%$ cold ethanol (v/v), dried, and re-suspended in deionized water. Genomic DNA samples were subjected to electrophoresis and visualized on a $1.0 \%$ agarose gel $(\mathrm{w} / \mathrm{v})$ stained with ethidium bromide, using a Transiluminator white/UV model LMW-20 UVP ${ }^{\circledR}$ system (Upland, CA, USA).

\section{Species-specific polymerase chain reaction (PCR)}

The oligonucleotides pair internal transcribed spacer 1 (ITS1) and ITS4, which were specific to selected fungal isolates, were used in the PCR assays. Forward primer (ITS1): TCCGTAGGTGAACCTGCGG and reverse primer (ITS4): TCCTCCGCTTATTGATATGC. The reaction mixture was prepared in a total volume of $25 \mu \mathrm{L}$, with a final concentration of $2 \mathrm{mM} \mathrm{MgCl}, 200 \mathrm{mM}$ Tris- $\mathrm{HCl}, \mathrm{pH} 8.4,500 \mathrm{mM} \mathrm{KCl}$, and $0.2 \mathrm{mM}$ of each dNTP. For each reaction, $0.04 \mathrm{U} / \mu \mathrm{L}$ Taq $5 \mathrm{U}$ polymerase (Invitrogen, Carlsbad, CA, USA), $0.2 \mu \mathrm{M}$ of each primer, and $1 \mu \mathrm{L}$ fungal template DNA were used. The reaction was performed in a Techne C-512 PCR system thermal cycler (Barloworld Scientific, Staffordshire, UK) using the following PCR conditions: denaturation at $95^{\circ} \mathrm{C}$ for $8 \mathrm{~min} ; 35$ cycles of denaturation at $95^{\circ} \mathrm{C}$ for $15 \mathrm{~s}$, annealing at $50^{\circ} \mathrm{C}$ for $20 \mathrm{~s}$, and extension at $72^{\circ} \mathrm{C}$ for $1 \mathrm{~min}$; final extension at $72^{\circ} \mathrm{C}$ for $5 \mathrm{~min}$; and cooling at $4^{\circ} \mathrm{C}$ until recovery of the samples (Carbone and Kohn, 1999). Amplification products were visualized on a $1.0 \%$ agarose gel $(\mathrm{w} / \mathrm{v})$ stained with ethidium bromide in a Transiluminator $3 \mathrm{UV}^{\mathrm{TM}}$ model LMS-20E UVP and analyzed using the program Quantity One version 4.2.1 (Bio-Rad, Hercules, CA, USA).

\section{DNA sequencing and analysis}

A standard PCR was used to amplify the ITS ribosomal gene region of samples. The 
primer pair ITS1 and ITS4 was used for PCR with annealing at $50^{\circ} \mathrm{C}$. After amplification, the products were directly sequenced using a sequencer 3730xI (Applied Biosystems, Foster City, CA, USA). All sequencing products were edited and analyzed using the software BioEdit version 7.1.3.0. Sequences were then used as a query to search for similarities using the BLAST network services on the NCBI website.

\section{Visual demonstration of fungal xylanases}

\section{Extracellular protein preparation}

After submerged fermentation, the supernatant was separated from the mycelium by filtration through a filter paper and then through a $0.45-\mu \mathrm{m}$ membrane. The filtrate was centrifuged at $3600 \mathrm{rpm}$ for $15 \mathrm{~min}$. The clarified protein extract was frozen at $-20^{\circ} \mathrm{C}$ for $24 \mathrm{~h}$ and dried in lyophilization equipment (Freeze Dry System/LYPH LOCK ${ }^{\circledR} 4.5$, Labconco, Kansas City, MO, USA) at $-40^{\circ} \mathrm{C}$ and $50 \times 10^{-3} \mathrm{Mbar}$ vacuum pressure. The protein was used for electrophoretic assays.

\section{Polyacrylamide gel electrophoresis}

Sodium dodecyl sulfate-polyacrylamide gel electrophoresis was conducted under denaturing conditions. A discontinuous gel was prepared with a $4 \%$ stacking gel and $17 \%$ resolving gel containing $0.015 \%$ birch wood xylan $(\mathrm{w} / \mathrm{v})$. For electrophoresis, $11 \mu \mathrm{g}$ concentrated protein was applied. The following molecular weight standards (Bio-Rad) were used (Da): triose phosphate isomerase $(26,625)$, myoglobin $(16,950), \alpha$-lactalbumin $(14,437)$, aprotinin (6512), insulin B chain (3496), and bacitracin (1423). Electrophoresis was carried out at 110 $\mathrm{V}$ for $1.6 \mathrm{~h}$ in an ice bath.

\section{Zymogram analysis}

After electrophoresis, the gel was stained according to the modified method of Khucharoenphaisan et al. (2010). The gel was rinsed in $50 \mathrm{mM}$ sodium citrate buffer, $\mathrm{pH}$ 5.0, for $1 \mathrm{~h}$ at $4{ }^{\circ} \mathrm{C}$ and incubated in the same buffer at $50^{\circ} \mathrm{C}$ for $72 \mathrm{~h}$. The gel was washed several times with deionized water and then stained for xylanase activity with $0.1 \%$ Congo red dissolution (w/v) for $30 \mathrm{~min}$ at room temperature. Finally, the gel was washed with $1 \mathrm{M} \mathrm{NaCl}$ to remove excess dye and then fixed with $0.5 \%$ acetic acid $(\mathrm{v} / \mathrm{v})$.

\section{Silver staining}

The gel was incubated for $1 \mathrm{~h}$ in a methanol, acetic acid, and deionized water mixture $(40: 10: 50, \mathrm{v} / \mathrm{v})$, to fix the proteins. The gel was washed for $24 \mathrm{~h}$ with several changes of deionized water and incubated in $0.02 \%$ sodium thiosulfate $(\mathrm{w} / \mathrm{v})$ for $1 \mathrm{~min}$. The gel was washed again 3 times with deionized water for $60 \mathrm{~s}$ and incubated in $0.1 \%$ silver nitrate $(\mathrm{w} / \mathrm{v})$ with $0.02 \%$ formaldehyde $(\mathrm{v} / \mathrm{v})$ at $4^{\circ} \mathrm{C}$ for $20 \mathrm{~min}$. The gel was washed 3 times with deionized water for $60 \mathrm{~s}$ and placed in a new staining tray of silver nitrate. The gel bands were developed in $3 \%$ sodium carbonate $(\mathrm{w} / \mathrm{v})$ with $0.05 \%$ formaldehyde $(\mathrm{v} / \mathrm{v})$. This developing solution was changed immediately after it turned yellow. Finally, the gel was washed with deionized water for $20 \mathrm{~s}$ and staining was terminated with $5 \%$ acetic acid (v/v) for $5 \mathrm{~min}$. 


\section{Data analysis}

\section{Correspondence analysis}

Correspondence analysis was conducted to study the association or dependence level among fungal isolates and their response to culture conditions. Categorical variables such as fungal growth on solid medium (FG), xylanolytic index (XI), xylanolytic activity (XA), and cellulolytic activity (CA) were recorded to facilitate the selection of the best fungal isolates. The growth of fungal isolates on solid medium was determined by calculating the ratio of colony diameter divided by the time of incubation. Categorical variables were organized in a 2-way matrix. The variables FG, XI, XA, and CA were assigned to columns and fungal isolates were assigned to rows. The mean of the values was used for statistical analysis. The distance between points in a bi-dimensional space indicates the level of similarity or affinity between categorical variables. A smaller distance between categorical variables indicates greater similarity.

\section{Statistical analysis}

The confidence interval was used to compare XI mean values of all fungi, with $95 \%$ confidence representing a statistically significant difference. In correspondence analysis, the difference between observed and expected frequencies was used to compare categorical variables. The observed frequency must be greater than the expected frequency to confirm that affinity between categorical variables exists, considering the hypothesis of independence among variables. A more similar numerical value of the difference between frequencies indicates higher affinity or dependency. Data were analyzed using the software Statistica version 8 (StatSoft, Inc., Tulsa, OK, USA).

\section{RESULTS}

\section{Profile of xylanolytic and cellulolytic activities of fungal isolates}

The 103 fungal isolates were cultivated with xylan as the sole carbon source. In solid medium, 2 groups of fungi were classified based on their XI (Figures 1A and 2). Sixty fungal isolates, those with the highest XI, were analyzed together in the first fungal work group to identify additional classification parameters. After the submerged fermentation process, xylanolytic and cellulolytic activities were measured. Xylanolytic activity values were graphed from high to low (Figure 1B).

Under the conditions used in the experimental assay, 2 groups of fungi were highlighted. One group showed only xylanolytic activity, while the other group showed both xylanolytic and cellulolytic activities. A total of $39 \%$ of fungi studied showed no cellulolytic activity (Table 1).

\section{Selection of the fungal group to study xylanolytic and cellulolytic activities}

Fungal isolates were grouped based on the identification of systematic relationships between the values of the variables FG, XI, XA, and CA (Figure 3). Fungi were distributed 
A.

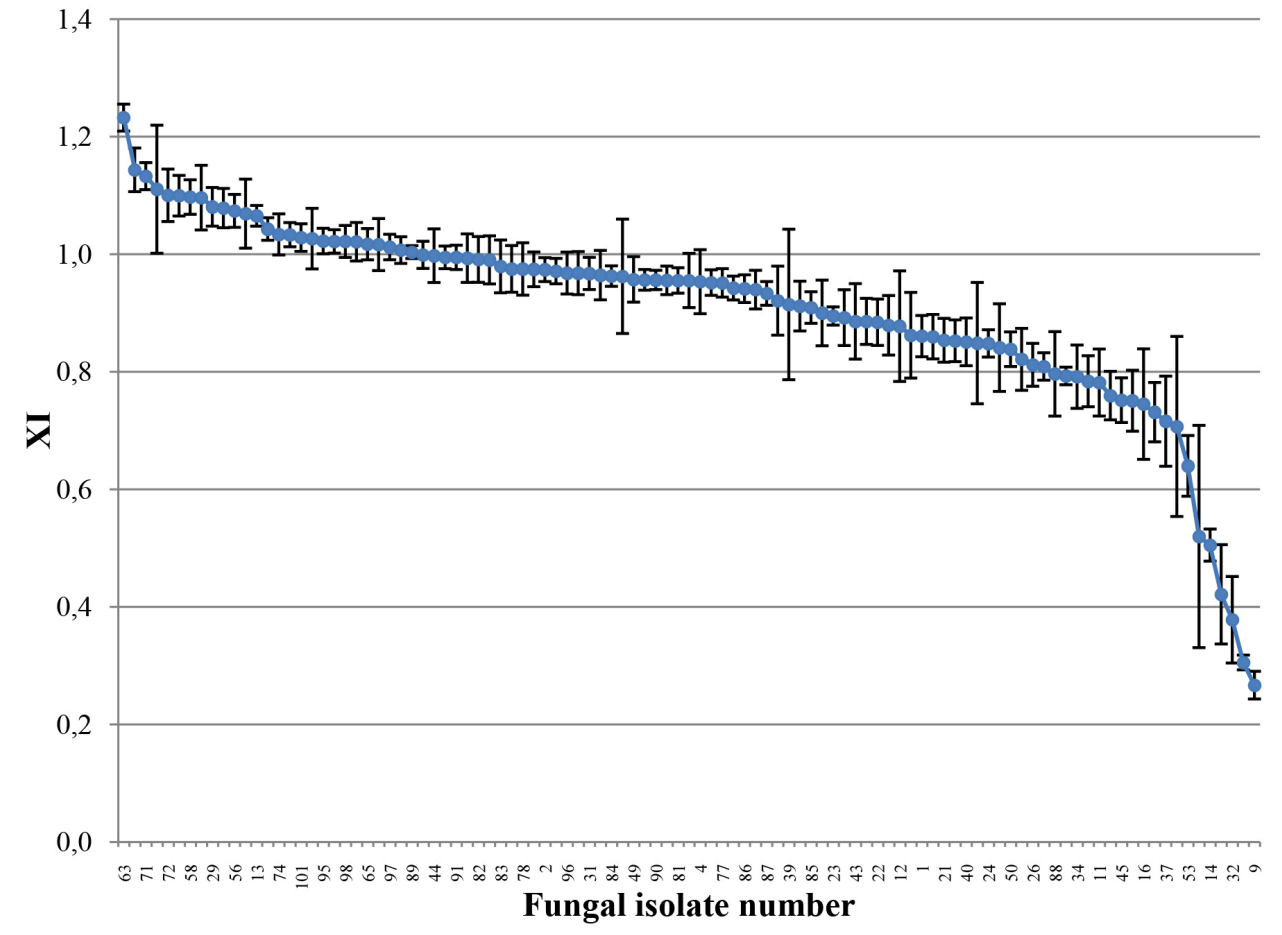

B.

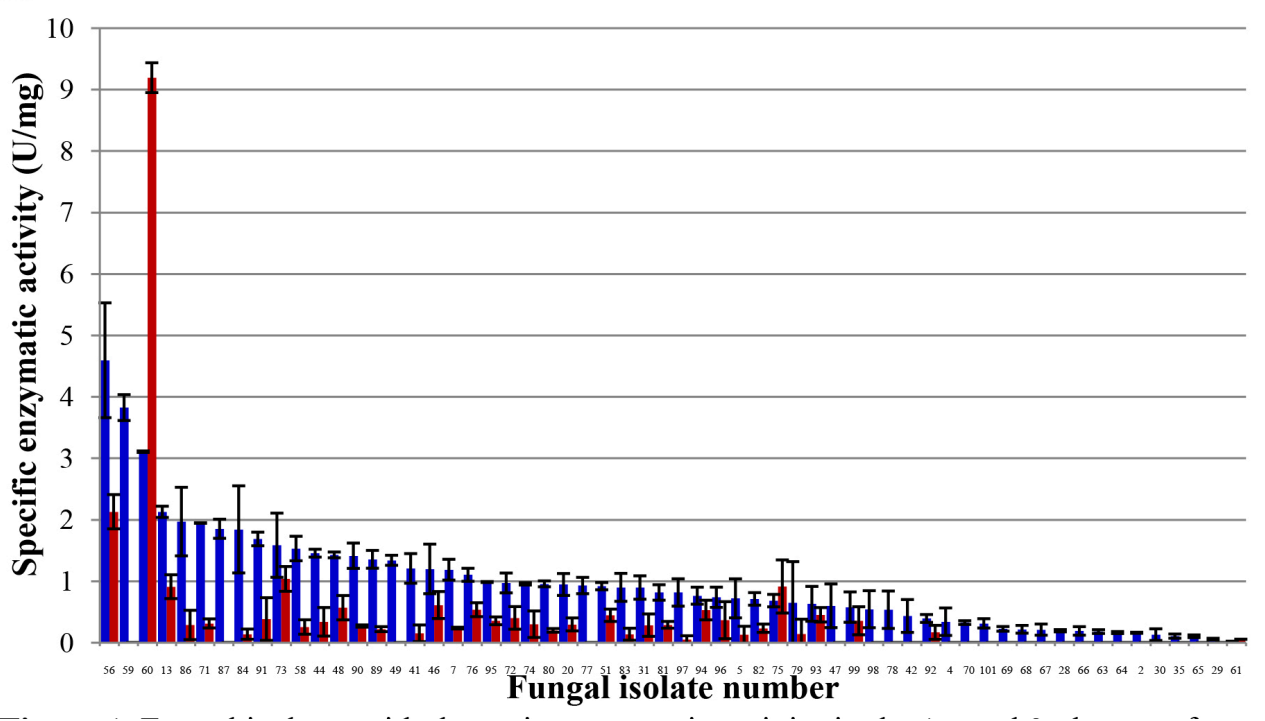

Figure 1. Fungal isolates with the major enzymatic activity in the first and second steps of selection. A. XI profile of one hundred and three fungal isolates. XI means \pm confidence interval $[=2.201 * \mathrm{SD} / \sqrt{ } 11] 95 \%, \mathrm{~N}=2$. B. Profile of xylanolytic and cellulolytic activity of sixty fungal isolates with the greatest XI. Blue columns $=$ xylanolytic activity $(\mathrm{U} / \mathrm{mg})$; red columns $=$ cellulolytic activity $(\mathrm{U} / \mathrm{mg})$. Enzymatic activity $\pm \mathrm{SD}, \mathrm{N}=3$. 

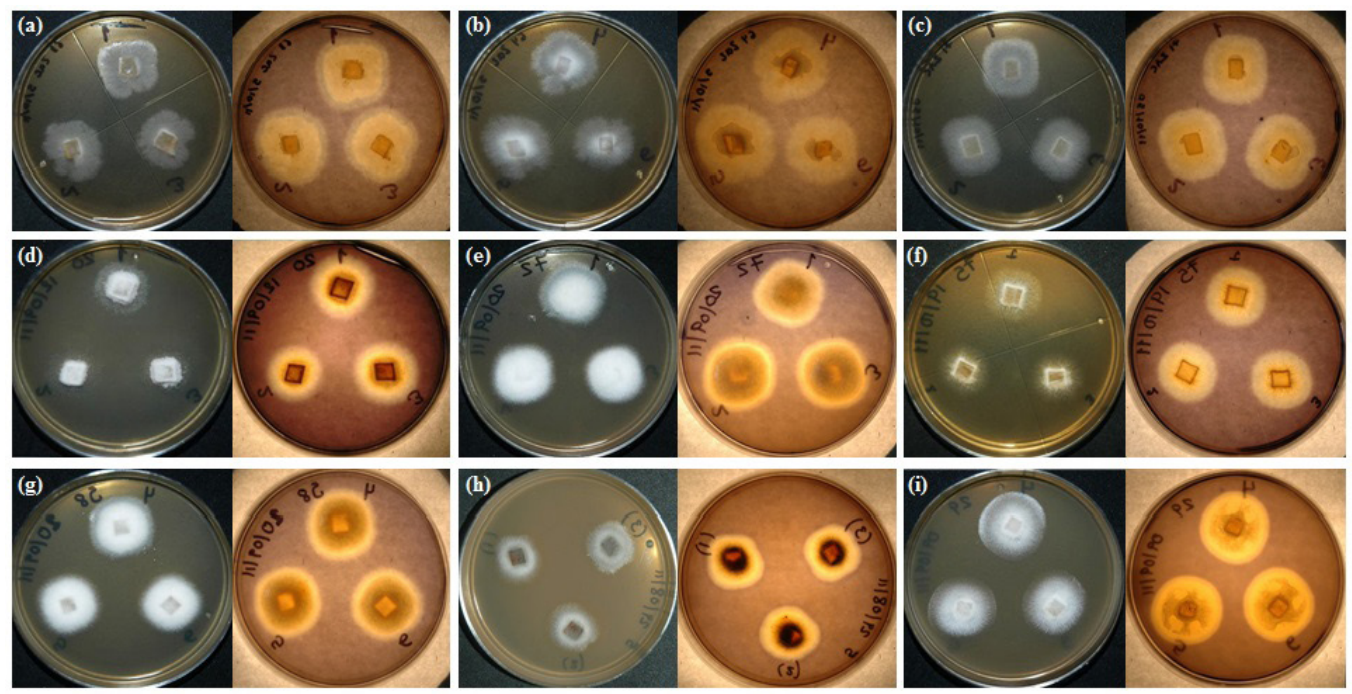

Figure 2. Fungal isolates with the greatest XI. Isolates: (a) 63; (b) 64; (c) 71; (d) 20 (Phomopsis viticola 5480); (e) 72; (f) 75; (g) 58; (h) 5 (Alternaria sp); (i) 29 (Fusarium solani Ch8p4-1).

in several zones within a Cartesian plane corresponding to a variable of major weight using correspondence analysis. A group of fungi was located near FG and XI because they showed significant similarity. Another group of fungi located between the XI and XA exhibited considerable XI and xylanolytic activity. Isolate 60 was located very close to CA, which was consistent with the out standing cellulolytic activity observed in liquid medium. However, the behavior of isolates 56,59, and 60 differed from the other group members. They showed great dissimilarities among themselves. A strong association was observed between the XI and FG parameters. Behavioral patterns were determined by comparing fungal isolates for selection from a group with similar characteristics (Figure 3). A group of fungi was selected based on its proximity to the XA variable. The numbers in bold correspond to fungal isolates with the highest affinity. Most fungal isolates in this group belonged to horticultural ecosystems, except 13 and 20, which were from orchard ecosystems. The fungal isolates $41,44,48,49,58,59,71$, $84,86,87,89,90$, and 91 were obtained from the same geographical region.

Statistically, variables in which observed frequencies were higher than expected frequencies (OF-EF) were similar, which was in accordance with the hypothesis of independence among variables. Fungal isolates 13, 41, 58, 59, 71, 84, 86, 87, and 91 showed the highest OF-EF value and had the greatest contribution to the total activity in the group of fungal isolates (Table 2).

\section{Molecular identification of xylanolytic fungi}

Based on the criteria above, these fungal isolates were selected for molecular identification. Selected fungal isolates were tested using the species-specific primers ITS1 and ITS4. All isolates yielded PCR products using this primer pair (Figure 4). Eight of the 9 selected isolates were species from the Fusarium genus (Table 3). 
Table 1. First selection of sixty fungal isolates with the greatest XI.

\begin{tabular}{|c|c|c|c|c|}
\hline Isolated No. & Ecosystem & XI & Xylanolytic activity (U/mg) & Cellulolytic activity (U/mg) \\
\hline 63 & 3 & $1.232 \pm 0.023$ & $0.178 \pm 0.030$ & $0.000 \pm 0.000$ \\
\hline 64 & 3 & $1.143 \pm 0.037$ & $0.162 \pm 0.016$ & $0.000 \pm 0.000$ \\
\hline 71 & 3 & $1.133 \pm 0.023$ & $1.944 \pm 0.004$ & $0.311 \pm 0.074$ \\
\hline 20 & 2 & $1.110 \pm 0.109$ & $0.944 \pm 0.178$ & $0.294 \pm 0.106$ \\
\hline 72 & 3 & $1.100 \pm 0.045$ & $0.969 \pm 0.162$ & $0.401 \pm 0.184$ \\
\hline 75 & 3 & $1.099 \pm 0.035$ & $0.682 \pm 0.101$ & $0.912 \pm 0.432$ \\
\hline 58 & 3 & $1.097 \pm 0.029$ & $1.529 \pm 0.199$ & $0.252 \pm 0.117$ \\
\hline 5 & 1 & $1.096 \pm 0.055$ & $0.719 \pm 0.318$ & $0.126 \pm 0.108$ \\
\hline 29 & 3 & $1.080 \pm 0.033$ & $0.054 \pm 0.015$ & $0.000 \pm 0.000$ \\
\hline 30 & 3 & $1.078 \pm 0.033$ & $0.128 \pm 0.095$ & $0.000 \pm 0.000$ \\
\hline 56 & 3 & $1.074 \pm 0.028$ & $4.593 \pm 0.934$ & $2.129 \pm 0.278$ \\
\hline 7 & 1 & $1.069 \pm 0.059$ & $1.185 \pm 0.169$ & $0.234 \pm 0.014$ \\
\hline 13 & 2 & $1.065 \pm 0.018$ & $2.127 \pm 0.091$ & $0.908 \pm 0.194$ \\
\hline 99 & 3 & $1.043 \pm 0.019$ & $0.576 \pm 0.247$ & $0.354 \pm 0.228$ \\
\hline 74 & 3 & $1.033 \pm 0.035$ & $0.955 \pm 0.019$ & $0.298 \pm 0.216$ \\
\hline 73 & 3 & $1.033 \pm 0.021$ & $1.583 \pm 0.522$ & $1.035 \pm 0.201$ \\
\hline 101 & 3 & $1.028 \pm 0.023$ & $0.312 \pm 0.075$ & $0.000 \pm 0.000$ \\
\hline 61 & 3 & $1.026 \pm 0.052$ & $0.021 \pm 0.001$ & $0.052 \pm 0.002$ \\
\hline 95 & 3 & $1.022 \pm 0.022$ & $0.984 \pm 0.007$ & $0.353 \pm 0.063$ \\
\hline 46 & 3 & $1.022 \pm 0.020$ & $1.198 \pm 0.404$ & $0.609 \pm 0.220$ \\
\hline 98 & 3 & $1.022 \pm 0.027$ & $0.542 \pm 0.301$ & $0.000 \pm 0.000$ \\
\hline 68 & 3 & $1.021 \pm 0.033$ & $0.215 \pm 0.063$ & $0.000 \pm 0.000$ \\
\hline 65 & 3 & $1.017 \pm 0.027$ & $0.102 \pm 0.021$ & $0.000 \pm 0.000$ \\
\hline 35 & 3 & $1.016 \pm 0.044$ & $0.104 \pm 0.034$ & $0.000 \pm 0.000$ \\
\hline 97 & 3 & $1.012 \pm 0.022$ & $0.814 \pm 0.223$ & $0.049 \pm 0.021$ \\
\hline 66 & 3 & $1.007 \pm 0.023$ & $0.188 \pm 0.069$ & $0.000 \pm 0.000$ \\
\hline 89 & 3 & $1.003 \pm 0.011$ & $1.354 \pm 0.145$ & $0.217 \pm 0.040$ \\
\hline 79 & 3 & $0.999 \pm 0.023$ & $0.649 \pm 0.466$ & $0.139 \pm 0.041$ \\
\hline 44 & 3 & $0.997 \pm 0.046$ & $1.454 \pm 0.064$ & $0.337 \pm 0.232$ \\
\hline 48 & 3 & $0.994 \pm 0.019$ & $1.426 \pm 0.047$ & $0.567 \pm 0.198$ \\
\hline 91 & 3 & $0.994 \pm 0.021$ & $1.685 \pm 0.111$ & $0.382 \pm 0.307$ \\
\hline 60 & 3 & $0.993 \pm 0.041$ & $3.106 \pm 0.012$ & $9.192 \pm 0.243$ \\
\hline 82 & 3 & $0.991 \pm 0.039$ & $0.710 \pm 0.103$ & $0.232 \pm 0.068$ \\
\hline 42 & 3 & $0.990 \pm 0.041$ & $0.432 \pm 0.268$ & $0.000 \pm 0.000$ \\
\hline 83 & 3 & $0.979 \pm 0.045$ & $0.898 \pm 0.228$ & $0.134 \pm 0.098$ \\
\hline 70 & 3 & $0.975 \pm 0.040$ & $0.324 \pm 0.030$ & $0.000 \pm 0.000$ \\
\hline 78 & 3 & $0.975 \pm 0.045$ & $0.533 \pm 0.304$ & $0.000 \pm 0.000$ \\
\hline 93 & 3 & $0.974 \pm 0.030$ & $0.629 \pm 0.284$ & $0.451 \pm 0.117$ \\
\hline 2 & 1 & $0.974 \pm 0.020$ & $0.159 \pm 0.009$ & $0.000 \pm 0.000$ \\
\hline 47 & 3 & $0.971 \pm 0.022$ & $0.598 \pm 0.356$ & $0.000 \pm 0.000$ \\
\hline 96 & 3 & $0.968 \pm 0.036$ & $0.736 \pm 0.164$ & $0.363 \pm 0.302$ \\
\hline 51 & 3 & $0.968 \pm 0.037$ & $0.917 \pm 0.059$ & $0.443 \pm 0.100$ \\
\hline 31 & 3 & $0.967 \pm 0.027$ & $0.895 \pm 0.190$ & $0.282 \pm 0.182$ \\
\hline 59 & 3 & $0.964 \pm 0.042$ & $3.823 \pm 0.210$ & $0.000 \pm 0.000$ \\
\hline 84 & 3 & $0.963 \pm 0.017$ & $1.841 \pm 0.709$ & $0.136 \pm 0.083$ \\
\hline 41 & 3 & $0.962 \pm 0.097$ & $1.206 \pm 0.241$ & $0.150 \pm 0.106$ \\
\hline 49 & 3 & $0.957 \pm 0.039$ & $1.338 \pm 0.081$ & $0.000 \pm 0.000$ \\
\hline 80 & 3 & $0.956 \pm 0.018$ & $0.955 \pm 0.048$ & $0.197 \pm 0.030$ \\
\hline 90 & 3 & $0.956 \pm 0.016$ & $1.412 \pm 0.206$ & $0.268 \pm 0.018$ \\
\hline 67 & 3 & $0.955 \pm 0.024$ & $0.210 \pm 0.091$ & $0.000 \pm 0.000$ \\
\hline 81 & 3 & $0.955 \pm 0.022$ & $0.815 \pm 0.125$ & $0.288 \pm 0.055$ \\
\hline 94 & 3 & $0.955 \pm 0.046$ & $0.762 \pm 0.138$ & $0.528 \pm 0.160$ \\
\hline 4 & 1 & $0.953 \pm 0.054$ & $0.339 \pm 0.224$ & $0.000 \pm 0.000$ \\
\hline 92 & 3 & $0.952 \pm 0.022$ & $0.391 \pm 0.064$ & $0.165 \pm 0.114$ \\
\hline 77 & 3 & $0.951 \pm 0.024$ & $0.927 \pm 0.133$ & $0.000 \pm 0.000$ \\
\hline 76 & 3 & $0.942 \pm 0.020$ & $1.102 \pm 0.106$ & $0.534 \pm 0.113$ \\
\hline 86 & 3 & $0.941 \pm 0.024$ & $1.968 \pm 0.558$ & $0.285 \pm 0.209$ \\
\hline 69 & 3 & $0.939 \pm 0.033$ & $0.222 \pm 0.038$ & $0.000 \pm 0.000$ \\
\hline 87 & 3 & $0.933 \pm 0.020$ & $1.851 \pm 0.155$ & $0.000 \pm 0.000$ \\
\hline 28 & 3 & $0.921 \pm 0.059$ & $0.191 \pm 0.019$ & $0.000 \pm 0.000$ \\
\hline
\end{tabular}

$\mathrm{XI} \pm$ confidence interval $(=2.201 * \mathrm{SD} / \sqrt{ } 11), 95 \%, \mathrm{~N}=2$. Enzymatic activity $\pm \mathrm{SD} .1)$ Forestry ecosystem, 2) horticultural ecosystem, 3) horticultural ecosystem. 


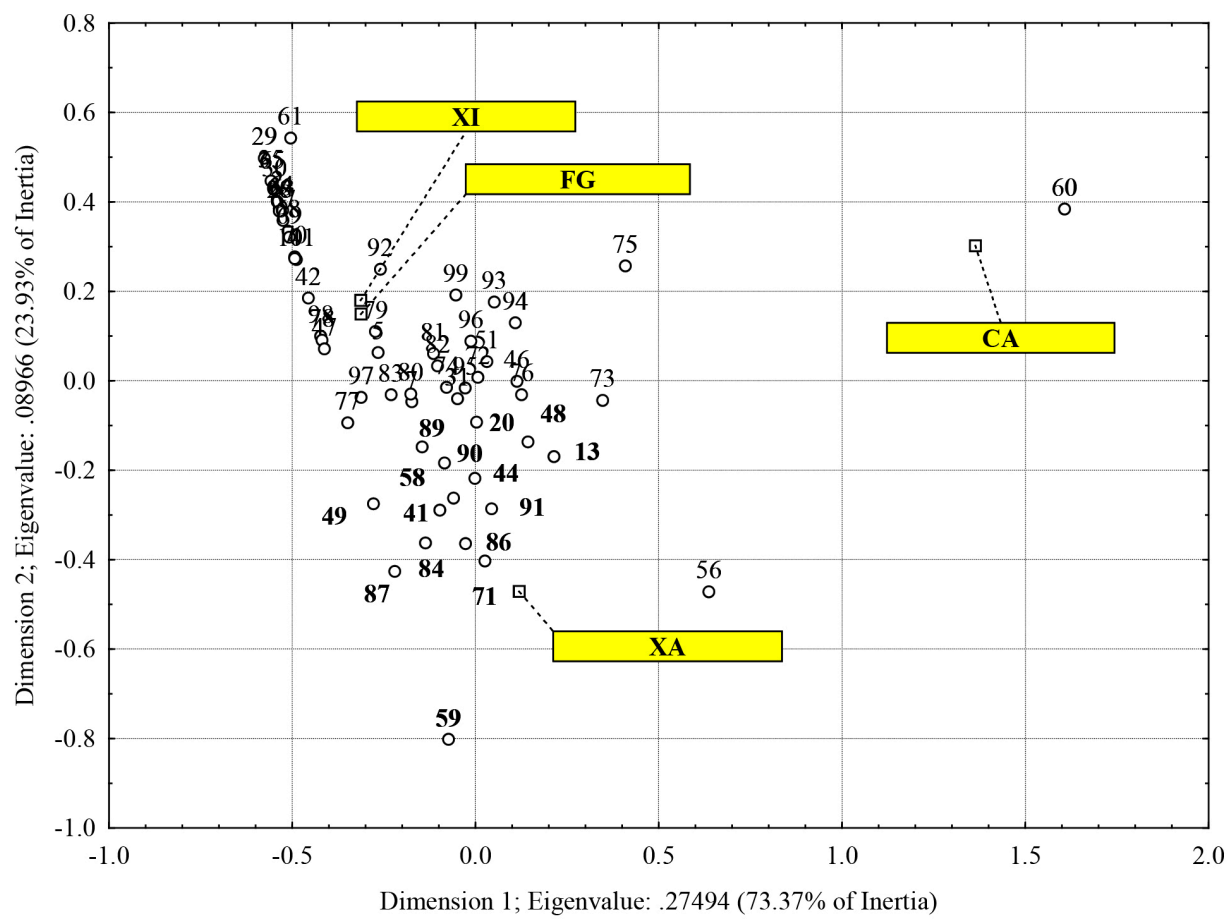

Figure 3. Distribution and grouping of the 60 fungal isolates from the 1 st selection step in function of categorical variables XI, FG, XA, and CA based on correspondence analysis. Points represent the relative position of each categorical variable. 2D plot of row and column coordinates; dimension: 1 x 2; input table: (rows x columns): $60 \mathrm{x}$ 4; standardization: row and column profiles (Statistica version 8). Circles $=$ fungal isolate, boxes $=$ response variable

Table 2. Second selection of fungal isolates with the highest affinity pattern based on correspondence analysis.

\begin{tabular}{lccc}
\hline Fungal isolate number & OF-EF $^{\mathrm{a}}$ & ${\text { Contribution to } \chi^{2}}^{\text {Percentage of xylanolytic activity }^{\mathrm{b}}}$ \\
\hline 71 & 0.7649 & 0.4962 & 3.31 \\
20 & 0.1334 & 0.0219 & 1.61 \\
58 & 0.4404 & 0.1780 & 2.61 \\
56 & 2.1644 & 1.9285 & 7.83 \\
13 & 0.5024 & 0.1554 & 3.63 \\
89 & 0.2194 & 0.0424 & 2.31 \\
44 & 0.3719 & 0.1278 & 2.48 \\
48 & 0.2837 & 0.0704 & 2.43 \\
91 & 0.5323 & 0.2458 & 5.29 \\
60 & -0.9978 & 0.2426 & 6.52 \\
59 & 2.1193 & 2.6358 & 3.14 \\
84 & 0.6415 & 0.3431 & 2.06 \\
41 & 0.3713 & 0.1652 & 2.28 \\
49 & 0.3597 & 0.1322 & 2.41 \\
90 & 0.2951 & 0.0780 & 3.35 \\
87 & 0.7094 & 0.3997 & 3.16 \\
\hline
\end{tabular}

${ }^{\mathrm{a}} \mathrm{OF}-\mathrm{EF}=$ observed frequency minus expected frequency. ${ }^{\mathrm{b} C a l c u l a t e d ~ f r o m ~ t o t a l ~ x y l a n o l y t i c ~ a c t i v i t y ~ f r o m ~ g r o u p ~}$ of sixty fungal isolates with the greatest XI [(xylanolytic activity of fungal isolated/xylanolytic activity of fungal population) $\mathrm{x} 100 \%]$. 


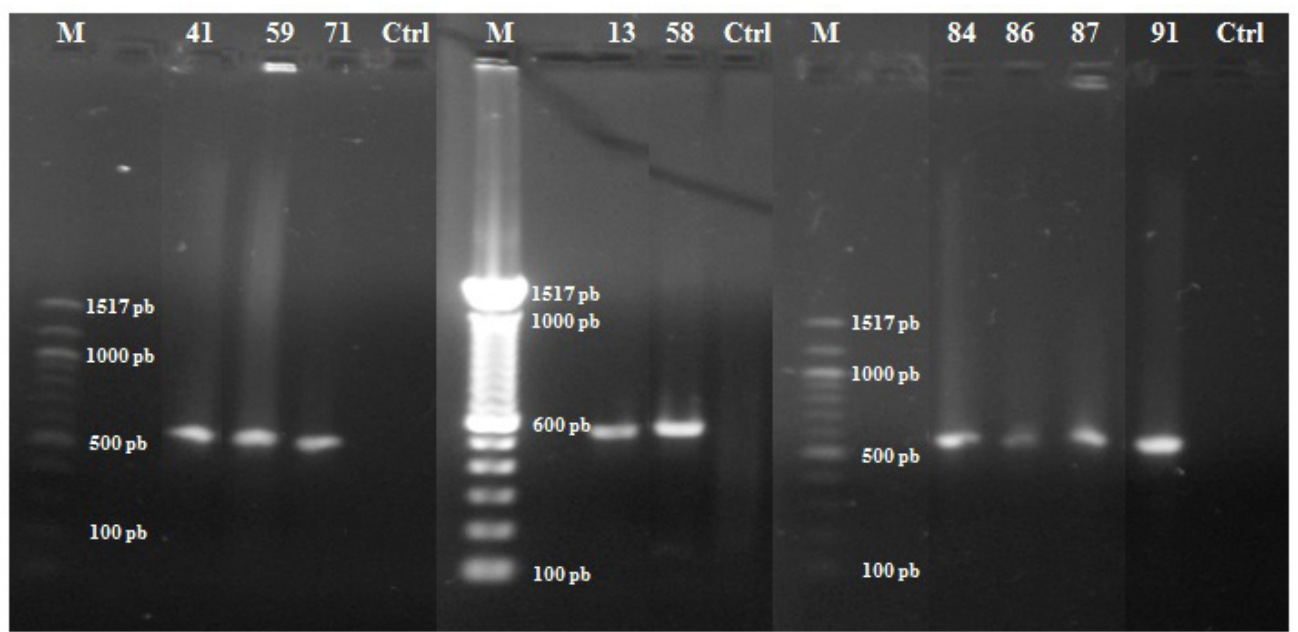

Figure 4. Amplified products from PCR. Lane $M=$ the molecular size marker, numbers indicate the DNA sample of fungal isolate, $\mathrm{Ctrl}$ is loading control.

Table 3. Identification of the nine selected fungi based on sequencing of the ITS ribosomal gene region (Mega BLAST, NCBI).

\begin{tabular}{llcr}
\hline Fungal isolate & Sequence based identification & Sequence with best match (accession No.) & Identity (\%) \\
\hline 13 & Phoma herbarum & JQ936331.1 & 99 \\
41 & Fusarium tricinctum & GU441584.1 & 100 \\
58 & Fusarium tricinctum & KF010839.1 & 100 \\
59 & Fusarium solani & KJ584550.1 & 100 \\
71 & Fusarium sp & HM486951.1 & 100 \\
84 & Fusarium solani & KJ584550.1 & 100 \\
86 & Fusarium solani & KF494125.1 & 100 \\
87 & Fusarium solani & KF494125.1 & 100 \\
91 & Fusarium tricinctum & HM486932.1 & 100 \\
\hline
\end{tabular}

Fusarium solani strains (59 and 87 ) showed the best xylanolytic/cellulolytic activity ratio, but, numerically, isolate 59 showed the best value relative to xylanolytic activity (Table 4 ).

Table 4. Fungal isolates with the greatest xylanolytic activity/cellulolytic activity ratio. Accession numbers provided by GenBank (NCBI) for new identified fungal isolates.

\begin{tabular}{lcc}
\hline Fungal isolate & Accession No. & Xylanolytic activity/cellulolytic activity ratio \\
\hline Phoma herbarum & KP144996 & 2.34 \\
Fusariumt ricinctum & KP137448 & 8.04 \\
Fusarium tricinctum & KP137447 & 6.07 \\
Fusarium solani & KP137443 & $\infty$ \\
Fusarium sp & KP137445 & 6.25 \\
Fusarium solani & KP137441 & 13.54 \\
Fusarium solani & KP137444 & 6.91 \\
Fusarium solani & KP137446 & $\infty$ \\
Fusarium tricinctum & KP137442 & 4.41 \\
\hline
\end{tabular}




\section{Zymogram analysis}

Xylanolytic activity of $F$. solani was determined using electrophoresis with separation under denaturing conditions. Zymogram analysis was performed to visualize the specific activity and the number of enzymes responsible of the observed activity (multiplicity of xylanases). Figure 5 shows the stained gels after electrophoresis. Lane 1 shows molecular weight markers, lanes 2 and 3 show the extracellular protein profile and zymogram of xylanolytic activity from F. solani (isolate 59), which were revealed using silver nitrate and Congo red, respectively. The zymogram showed 1 well with a defined, clear area resulting from enzyme hydrolysis of xylan; a matching band was observed on the silver-stained gel and had a molecular weight of $19 \mathrm{kDa}$.

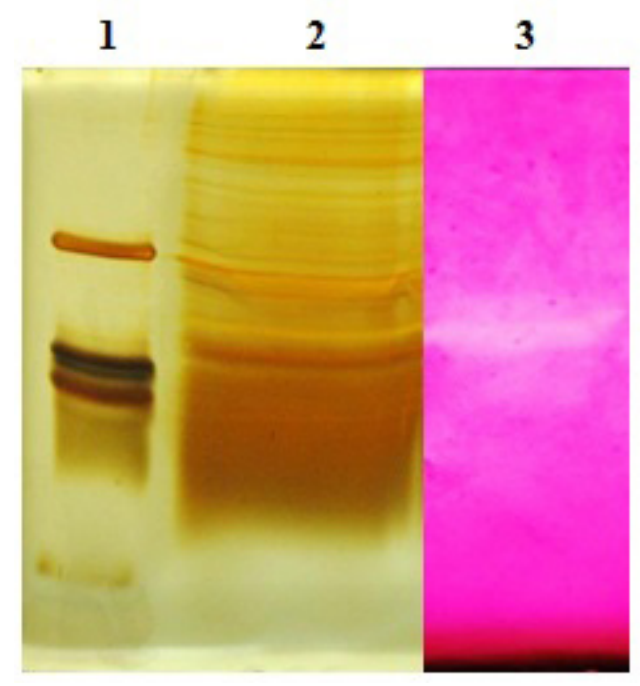

Figure 5. Electrophoresis gels. Lane $1=$ molecular weight markers (Da): triose phosphate isomerase $(26,625)$, myoglobin (16,950), $\alpha$-lactalbumin (14,437), aprotinin (6512), insulin B chain (3496), and bacitracin (1423); lanes 2 and $3=$ extracellular protein and zymogram xylanase activity of isolate 59, revealed with silver nitrate and Congo red, respectively.

\section{DISCUSSION}

Fungi were collected from different ecosystems and several tests were conducted to obtain a small group of fungal producers with interesting xylanolytic activity. All samples grew on solid medium with xylan as the sole carbon source. Sixty isolates were selected in the first fungal group, in which 27 fungal isolates showed an XI $\geq 1$.0. Fifty-four fungal isolates were from horticultural, 4 were from forest, and 2 were from orchard ecosystems.

Two groups of fungi were highlighted based on their extracellular enzyme production. The first group was distinguished because it showed only xylanolytic activity under the experimental conditions used. Motta et al. (2013) found that selective production of xylanase was possible using only xylan as a carbon source, as the mechanisms governing the formation of extracellular enzymes with regards to the carbon sources present in the medium are influenced by the availability of precursors for enzyme synthesis. Another fungal group showed 
both xylanolytic and cellulolytic activities. Fungal xylanases are generally associated with cellulases (Steiner et al., 1987), including those from species of Aspergillus, Thermomyces, Myceliophthora, Thermomucor, and Candida cultured on medium containing corn straw and cardboard as carbon sources under solid state fermentation (Moretti et al., 2012). In filamentous fungi, the production of plant cell wall-degrading enzymes (cellulases, hemicellulases, ligninases, and pectinases) is mainly regulated at the transcriptional level. Genes are induced in the presence of polymers, molecules derived from polymers, or other inducers. Significant crosstalk occurs regarding the induced expression of genes encoding for different classes of enzymes. For example, in some fungi under specific growth conditions, the same compounds may induce expression of both cellulases and hemicellulases. Additionally, coordinated transcriptional regulation by the activator $X \ln R$ has been observed at various levels during the extracellular production of xylanases and cellulases (van Peij et al., 1998; Aro et al., 2005).

A second screening was performed in 60 fungal isolates by using variables to discriminate and to select a second fungal group.

A strong association between the categorical variables XI and FG was observed. This indicates that fungal growth depended on nutrient type and the ability to secrete xylanolytic enzymes to degrade xylan present in the culture medium. Fungal isolates 13, 20, 41, 44, 48, $49,58,71,84,86,87,89,90$, and 91, among variables XI and XA, stood out for its ability to produce extracellular xylanases in both solid and liquid media. Fungal isolates 56, 59, and 60 showed behavioral pattern that differed from the rest of the group. These fungi are more distantly related to the other fungal isolates, indicating that the mechanisms and components of the genomic inventory used for regulation of plant cell wall-degrading enzymes are diverse in different fungi (Glass et al., 2013).

The identification of xylanolytic fungal isolates selected was conducted with molecular tools using the ITS ribosomal gene region (Summerell et al., 2010). One of them was identified as Phoma herbarum, which was isolated from avocado trees. The remaining 8 fungal isolates were species from the Fusarium genus, which were isolated from bean crop fields. Species belonging to the Phoma genus and related coelomycetes are often encountered as virulent plant pathogens (Aveskamp et al., 2008). Phoma herbarum is a cosmopolitan fungus that has gained global attention in recent years for its ability to produce many functional chemicals with potent activity (Goldring and Pattenden, 2006). Additionally, it causes severe diseases in a variety of hosts, including plants and vertebrates (Faisal et al., 2007; Tullio et al., 2010). However, few studies have examined the xylanolytic activity on Phoma species (Bradner et al., 1999; Yang et al., 2005; Bezerra et al., 2012).

The Fusarium genus includes more than 80 fungal species with considerable differences in their biology, ecology, and economic significance. This genus is well known in agriculture and forestry for the adverse effects of its phytopathogenic species as well as for their contaminant mycotoxins that may affect vertebrate health (Silvestro et al., 2013). Survival in these habitats implies that Fusarium spp are useful with respect to obtaining extracellular enzymes. However, information regarding the enzyme production abilities of Fusarium sp has not been thoroughly examined.

F. tricinctum is a food contaminant that produces toxic metabolites; its wide distribution in crops and plant products is well known. This fungus is frequently isolated from moldy grains such as corn and rice. Additionally, it is the causative agent of drowning and root rot in wheat (Bamburg et al., 1969). The effect of F. tricinctum extends beyond plants and their products. In vertebrates, this fungus causes mycotoxicosis after ingestion. In recent years, 
studies of F. tricinctum have focused on the purification and bioactivity analysis of toxigenic and antimicrobial substances produced by the fungus.

It has been shown that these cereal pathogens produce more xylanases than other cell wall-degrading enzymes. This feature may be related to the composition of graminaceous crops and grasses, as arabinoxylan accounts for up to $40 \%$ of cell walls. The presence of xylanases in several Fusarium species has been reported (Beliën et al., 2007). However, there have been no reports of $F$. tricinctum xylanolytic activity.

Fungal isolate 59 was selected in this study for its high extracellular xylanolytic activity in both solid and liquid cultures and by its lack of cellulolytic activity. This fungus was identified as F. solani, which is a promising organism for studying nutritional factors to improve the production of extracellular xylanases. There have been a few reports of efficient production of xylanase by F. solani, including the optimization of enzyme production (Obruca et al., 2012).

Zymogram analysis revealed the presence of xylanase activity as indicated by a clear hydrolysis zone in the gel stained with Congo red. Using the zymogram method, the multiplicity of xylanases in $F$. solani was absent, despite that several studies have reported the presence of multiple xylanases in filamentous fungi using the same method (Raghukumar et al., 2004).

The relative molecular weight of this enzyme was estimated to be $19 \mathrm{kDa}$. It was reported that endoxylanases have a low molecular weight (Mellon et al., 2011). However, additional studies are needed to determine other biochemical features of $F$. solani enzymes, such as isoelectric point, thermo stability, substrate specificity, and size of oligosaccharides produced as by-products. Further studies are necessary to confirm that the electrophoretic signal corresponds to a single enzyme. Nevertheless, enzyme multiplicity has been reported in other fungi, including Aspergillus sp fungi such as A. nidulans, A. oryzae, A. niger, and A. fumigatus (De Souza et al., 2011).

Fungi have determinant factors for the production of extracellular lytic enzymes, such as the composition and structure of cell wall, which differs among plant lineages. Additionally, the type of polysaccharides in the hemicellulose fraction varies between plants. Fungi associated with plants, saprophytes, or plant pathogens that inhabit various ecosystems can secrete specific hydrolytic enzymes to degrade these hetero-polysaccharides. Some lignocellulosic materials from horticultural crops contain a higher percentage of hemicelluloses than those from orchard and forest crops. This has been observed for barley straw, which contains 28$30 \%$ of hemicelluloses, an amount significantly higher than the amount present in pine wood, which contains only 8.8\% (Jørgensen et al., 2007). Because of this biological ability, most of the best selected fungi are located in horticultural ecosystems.

Fungal growth on xylan, in a lower nitrogen/carbon ratio and without cellulose contamination, is a strategy for producing xylanolytic systems free of cellulases. Additionally, the results obtained in the present study contribute to the potential for using P. herbarum, F. tricinctum, and $F$. solani to lyse hemicelluloses into as similable monomers. Therefore, these fungi are promising microorganisms that can be used in the design of a production method to obtain extracellular xylanases in large quantities, particularly isolate 59, identified as $F$. solani, which was selected for its ability to produce extracellular xylanases with biotechnological potential.

\section{ACKNOWLEDGMENTS}

Research supported by the UMSNH. M. Alvarez-Navarrete received a scholarship from Consejo Nacional de Ciencia y Tecnología, CONACyT (México). 


\section{REFERENCES}

Aro N, Pakula T and Penttilâ M (2005). Transcriptional regulation of plant cell wall degradation by filamentous fungi. FEMS Microbiol. Rev. 29: 719-739.

Aveskamp MM, De Gruyter J and Crous PW (2008). Biology and recent developments in the systematics of Phoma, a complex genus of major quarantine significance. Fungal Divers. 31: 1-18.

Bailey MJ, Biely P and Poutanen K (1992). Interlaboratory testing of methods for assay of xylanase activity. J. Biotechnol. 23: $257-271$.

Bamburg JR, Strong FM and Smalley EB (1969). Toxins from moldy cereals. J. Agric. Food Chem. 17: 443-450.

Beliën T, Van Campenhout S, Van Acker M, Robben J, et al. (2007). Mutational analysis of endoxylanases XylA and XylB from the phytopathogen Fusarium graminearum reveals comprehensive insights into their inhibitor insensitivity. Appl. Environ. Microb. 73: 4602-4608.

Bezerra JDP, Santos MGS, Svedese VM, Lima DMM, et al. (2012). Richness of endophytic fungi isolated from Opuntiaficus-indica Mill. (Cactaceae) preliminary screening for enzyme production. World J. Microbiol. Biotechnol. 28: 1989-1995.

Bradner JR, Sidhu RK, Gillings M and Nevalainen KM (1999). Hemicellulase activity of antarctic microfungi. J. Appl. Microbiol. 87: 366-370.

Cai L, Giraud T, Zhang N, Begerow D, et al. (2011). The evolution of species concepts and species recognition criteria in plant pathogenic fungi. Fungal Divers. 50:121-133.

Carbone I and Kohn LM (1999). A method for designing primer sets for speciation studies in filamentous ascomycetes. Mycologia 91: 553-556.

Chipeta ZA, du Preez JC, Szakacs G and Christopher L (2005). Xylanase production by fungal strains on spent sulphite liquor. Appl. Microbiol. Biotechnol. 69: 71-78.

De Souza W, de Gouvea PF, Savoldi M, Malavazi I, et al. (2011). Transcriptome analysis of Aspergillus niger grown on sugarcane bagasse. Biotechnol. Biofuels 4: 40.

Dhiman SS, Sharma J and Battan B (2008). Industrial applications and future prospects of microbial xylanases: review. Bioresources 3: 1377-1402.

Faisal M, Elsayed E, Fitzgerald SD, Silva V, et al. (2007). Outbreaks of phaeohyphomycosis in the chinook salmon (Oncorhynchus tshawytscha) caused by Phoma herbarum. Mycopathologia 163: 41-48.

Ghose TK (1987). Measurement of cellulase activities. Pure Appl. Chem. 59: 257-268.

Glass NL, Schmoll M, Cate JHD and Coradetti S (2013). Plant cell wall deconstruction by ascomycete fungi. Annu. Rev. Microbiol. 67: 477-498.

Goldring WPD and Pattenden G (2006). The phomactins: A novel group of terpenoid platelet activating factor antagonists related biogenetically to the taxanes. Acc. Chem. Res. 39: 354-361.

Jørgensen H, Kristensen JB and Felby C (2007). Enzymatic conversion of lignocellulose into fermentable sugars: Challenges and opportunities. Biofuel. Bioprod. Biorefin. 1: 119-134.

Khandeparker R and Numan MT (2008). Bifunctional xylanases and their potential use in biotechnology. J. Ind. Microbiol. Biotechnol. 35: 635-644.

Khucharoenphaisan K, Tokuyama S and Kitpreechavanich V (2010). Purification and characterization of a highthermostable $\beta$-xylanase from newly isolated Thermomyces lanuginosus THKU-49. Mycoscience 51: 405-410.

King BC, Waxman KD, Nenni NV, Walker LP, et al. (2011). Arsenal of plant cell wall degrading enzymes reflects host preference among plant pathogenic fungi. Biotechnol. Biofuels 4: 4.

Klein-Marcuschamer D, Oleskowicz-Popiel P, Simmons BA and Blanch HW (2012). The challenge of enzyme cost in the production of lignocellulosic biofuels. Biotechnol. Bioeng. 109: 1083-1087.

Lin RC, Ding ZS, Li LB and Kuang TY (2001). A rapid and efficient DNA minipreparation suitable for screening transgenic plants. Plant Mol. Biol. Rep. 19: 379a-379e.

Lowry OH, Rosenbrough NJ, Farr AL and Randall RJ (1951). Protein measurement with the folin phenol reagent. J. Biol. Chem. 193: 265-275.

Mellon JE, Cotty PJ, Callicott KA and Abbas H (2011). Identification of a major xylanase from Aspergillus flavus as a 14-kD protein. Mycopathologia. 172: 299-305.

Moretti MMS, Bocchini-Martins DA, Da Silva R, Rodrigues A, et al. (2012). Selection of thermophilic and thermotolerant fungi for the production of cellulases and xylanases under solid-state fermentation. Braz. J. Microbiol. 43: 1062-1071.

Motta FL, Andrade CCP and Santana MHA (2013). Sustainable degradation of lignocellulosic biomass - techniques, applications and commercialization. In: A review of xylanase production by the fermentation of xylan: classification, characterization and applications (Chandel AK and Da Silva SS, eds.). InTech, Rijeka, Croatia.

Genetics and Molecular Research 14 (3): 8100-8116 (2015) 
Obruca S, Marova I, Matouskova P, Haronikova A, et al. (2012). Production of lignocellulose-degrading enzymes employing Fusarium solani F-552. Folia Microbiol. 57: 221-227.

Pointing SB (1999). Qualitative methods for the determination of lignocellulolytic enzyme production by tropical fungi. Fungal Divers. 2: 17-33.

Raghukumar C, Muraleedharan U, Gaud VR and Mishra R (2004). Xylanases of marine fungi of potential use for biobleaching of paper pulp. J. Ind. Microbiol. Biot. 31: 433-441.

SIAVI. Sistema de Información Arancelaria Vía Internet de la Secretaría de Economía. http://200.77.231.38/. Accessed September 5, 2013.

Silvestro LB, Stenglein SA, Forjan H, Dinolfo MI, et al. (2013). Occurrence and distribution of soil Fusarium species under wheat crop in zero tillage. Span. J. Agric. Res. 11: 72-79.

Steiner W, Lafferty RM, Gomes I and Esterbauer H (1987). Studies on a wild type strain of Schizophyllum commune: Cellulase and xylanase production and formation of the extracellular polysaccharide schizophyllan. Biotechnol. Bioeng. 30: 169-178.

Summerell BA, Laurence MH, Liew ECY and Leslie JF (2010). Biogeography and phylogeography of Fusarium: a review. Fungal Divers. 44: 3-13.

Tullio V, Banche G, Allizond V, Roana J, et al. (2010). Non-dermatophyte moulds as skin and nail foot mycosis agents: Phoma herbarum, Chaetomium globosum and Microascus cinereus. Fungal Biol. 114: 345-349.

van Peij NN, Gielkens MM, de Vries RP, Visser J, et al. (1998). The transcriptional activator XlnR regulates both xylanolytic and endoglucanase gene expression in Aspergillus niger. Appl. Environ. Microbiol. 64: 3615-3619.

Yang XB, Gao XD, Han F, Xu BS, et al. (2005). Purification, characterization and enzymatic degradation of YCP, a polysaccharide from marine filamentous fungus Phoma herbarum YS4108. Biochimie 87: 747-754. 